\title{
Sweating, dehydration and prevention of heatstroke
}

\section{Sudoración, deshidratación y prevención del golpe de calor}

\author{
Ildefonso Alvear-Ordenes \\ Laboratorio de Fisiología Aplicada (FISAP). Instituto de Biomedicina (IBIOMED) y Departamento de Ciencias Biomédicas. Universidad de León.
}

doi: $10.18176 /$ archmeddeporte.00037

In the thermoregulatory system, the sweat glands respond to a complex physiological relationship between the central nervous system, the cardiovascular system and the skin. At rest, $80 \%$ of heat is dissipated by conduction, convection and radiation. When ambient temperature exceeds the temperature of the skin, $\sim 32^{\circ} \mathrm{C}$, these mechanisms are no longer effective and the body starts to secrete sweat, taking over the evaporation of $80 \%$ of the dissipated heat. It is necessary to maintain a balanced body temperature for the organism to work correctly and, increasing the internal temperature by more than a couple of degrees has significant physiological consequences that might even be lifethreatening.

To maintain a normal internal temperature $\left(36.8 \pm 0.5^{\circ} \mathrm{C}\right)$, the maximum temperature of the skin is required to be $35^{\circ} \mathrm{C}$, to thereby produce an appropriate temperature gradient from the core to the skin. In this mechanism, an increase in relative air humidity will progressively and significantly reduce evaporation by sweating. These effects can be compensated by the wind that facilitates evaporation and its radiating effect. In any case, and without considering environmental conditions, there are very few types of exercise that produce enough wind speed itself for this, such as cycling.

In any of the conditions observed above, hydration is fundamental. Almost 80 years ago, the effects of physical performance in a hot atmosphere had already been observed, demonstrating the need to ingest liquids to replace losses due to sweat. 'I should also be considered that there are considerable differences in daily hydration $(0.74 \mathrm{~L} /$ day to $2.70 \mathrm{~L} /$ day) among healthy young adults. ${ }^{2}$ Furthermore, it has been observed that in sport, continuous exercise and intermittent exercise do not have the same effect on hydration efficiency, and the latter is more efficient. ${ }^{3}$ Scientific entities update this knowledge cyclically leading to a considerable number of recommendations on hydration, euhydration and hydration with supplementation, even in special environments. ${ }^{4}$
There are specific recommendations to avoid pathologies associated with heat caused by effort. ${ }^{5}$

In situations of heat stress, increased activity in the vasodilation system is responsible for $80 \%$ to $90 \%$ of the increase in blood flow to the skin. During exercise, blood supply to the active muscles and blood flow to the skin to dissipate heat come into conflict, both are important in thermal regulation, regulation of arterial pressure, to cover metabolic needs, and in cardiovascular homoeostasis. These conditions seem to be associated with dehydration when the water loss is greater than $2 \%$, $2-3 \%$ or $4 \%$ of body mass. Consequently, exercising when dehydrated, particularly in a hot atmosphere, can increase the risk of heat-related illnesses, including heat stroke. However, working from studies performed on more than 5,000 soldiers, only $17 \%$ of cases were associated with dehydration. ${ }^{6}$ Heatstroke seems to be more associated with other factors such as acclimatising to the heat, medicines, genetic predisposition and injuries. ${ }^{4,6}$ It has also been observed that incidence of heatstroke has increased greatly since the 1980s. In the USA alone, more than 3,300 deaths were attributed to this cause between 2006 and 2010.

At rest, urination is the best way of eliminating liquid, followed by the skin, respiration, faecal matter and sweat. However, when exercising, in a hot atmosphere, or a combination of the two, the situation is completely reversed. There is a great interest in finding out about and pinpointing biomarkers that represent both hydration and dehydration. These biomarkers can be found by collecting urine samples (osmolality, specific severity, colour, volume; considered to be non-invasive measurements) ${ }^{4}$ or plasma/saline solution (osmolality, vasopressin, etc.). Biomarkers are considered to be just as important as the actual measurement of difference in body mass $s^{3,4}$.

Dehydration induced by sweating not only causes changes in these markers but a loss of electrolytes that must be recovered, such as sodium. ${ }^{4,5}$ Consequently, sweating during exercise also makes it possible

Correspondencia: Ildefonso Alvear-Ordenes

E-mail: ialvor@unileon.es 
to eliminate significant quantities of ammonia, urea and lactate, among other metabolic residue.

Dehydration can endanger life and affect not only athletes but also vulnerable populations. The situation is worsening for these populations due to climate change. There is a progressive spread of geographic areas that reach dry-bulb temperatures above $33^{\circ} \mathrm{C}$ or $35^{\circ} \mathrm{C}$.

The stability point for our supposed heat-regulating centre, on the anterior hypothalamus, seems to change its control point in some conditions (fever or heatstroke). It is important to mention that it remains unclear that our hypothalamus is the only integrative centre or controller that determines our temperature stability. It has been suggested that other independent centres might exist, including the hypothalamus that, with their own afferent and efferent branches, manage to coordinate around a common variable that is body temperature ${ }^{8,9}$. It is possible that the classic heat-regulating mode ${ }^{10}$ might change considerably over time.

During prolonged exercise in a hot atmosphere over a long period of time, sweat production will drop and body temperature will rise, with cutaneous vasodilation, decrease in blood volume, renal flow and the antidiuretic hormone; a phenomenon that has been called "Sweating fatigue" that will reduce the capacity to respond to exercise. The low blood volume will cause inefficient muscular irrigation, intense fatigue, with an increase in the HR, less sweating and a high risk of hyperthermia, cardiac syncope and risk of death. Although temperature modifies the heart's vagal response, using heart rate as a control variable does not help us identify sweating fatigue.

Biosensor technology has been developed over the last 30 years. The use of non-invasive biosensors directly on the skin, making the most of the electric surface characteristics and/or the actual composition of sweat, is not a new idea. It is worth remembering that, although it seems mundane, a heart rate monitor is also a biosensor. Over the last few years, studies on biosensors have really taken off. An average of over 60 articles have been published every year. Since the 1990s, one of the first papers on biosensors began by testing an inefficient biosensor for amino acids and another for L-lactate ${ }^{11}$.

Many of the biosensors being developed are intended for diagnosis or screening of pathologies, such as the case of glucose sensitive patches. These biosensors can be built into products or fabric clothing, they can also be designed as different models of patches or encapsulated systems that cover the skin. Some studies on biosensors associated with physical activity deserve a mention, such as the system to record bipolar ECG. This uses a system similar to headphones for ears, also making it possible to record sweat rate, $\mathrm{pH}$ and lactate ${ }^{12}$. In another study, nanoparticles have been used, built into a normal filter base, that was designed to measure sweat rate, and sweat loss ${ }^{13}$.

When these contraptions are small enough with sufficient autonomy, they can be used to control athletes during sport. Of course, there are protocols for treatments against heatstroke, but the key to the problem revolves around seeking detection measures to stop it happening.

\section{Bibliography}

1. Pitts GC, Johnson RE, Consolazio FC. Work in the heat as affected by intake of water salt and glucose. Amer J Physiol. 1944;142(2):253-9.

2. Perrier E, Vergne $S$, Klein A, Poupin M, Rondeau P, Le Bellego L, et al. Hydration biomarkers in free-living adults with different levels of habitual fluid consumption. Br J Nutr. 2013;109(9):1678-87.

3. Rivera-Brown AM, Ramírez-Marreno FA, Frontanés J, Rosario RA, Hernández OJ. Sweating and core temperature in athletes training in continuous and intermittent sports in tropical climate. Arch Med Deporte. 2019;36(2):86-91.

4. Sawka MN, Burke LM, Eichner ER, Maughan RJ, Montain SJ, Stachenfeld NS. Medicine position stand. Exercise and fluid replacement American College of Sports. Med Sci Sports Exerc. 2007;39(2):377-90.

5. Casa DJ, DeMartini JK, Bergeron MF, Csillan D, Eichner ER, Lopez RM, et al. Nationa Athletic Trainers' Association Position Statement: Exertional Heat Illnesses. J Ath/ Train. 2015;50(9):986-1000. Erratum en: J Ath/ Train. 2017;52(4):401.

6. Carter R 3rd, Cheuvront SN, Williams JO, Kolka MA, Stephenson LA, Sawka MN, et al. Hospitalizations and death from heat illness in US Army soldiers, 1980-2002. Med Sci Sports Exerc. 2005;37(8):1338-44.

7. Raymond C, Matthews T, Horton RM. The emergence of heat and humidity too severe for human tolerance. Sci Adv. 2020;6(19):eaaw1838.

8. Romanovsky AA. Thermoregulation: some concepts have changed. Functional architecture of the thermoregulatory system. Am J Physiol Regul Integr Comp Physiol. 2007;292(1):R37-46.

9. Imeri L. Thermoregulation as a non-unified system: A difficult to teach concept. Temperature (Austin). 2017;19;4(1):1-8.

10. Smiles KA, Elizondo RS, Barney CC. Sweating responses during changes of hypothalamic temperature in the rhesus monkey. J Appl Physiol. 1976;40(5):653-7.

11. Laccourreye $O$, Bernard $D$, de Lacharière $O$, Bazin $R$, Jouffre $V$, Brasnu D. Apport des biocapteurs enzymatiques à I lactate et à acide aminé pour l'analyse du syndrome de Frey. Ann Otolaryngol Chir Cervicofac. 1994;111(6):347-52.

12. Gil B, Anastasova S, Yang GZ. A Smart Wireless Ear-Worn Device for Cardiovascular and Sweat Parameter Monitoring During Physical Exercise: Design and Performance Results. Sensors (Basel). 2019;19(7):1616

13. Parrilla M, Guinovart T, Ferré J, Blondeau P, Andrade FJ. A Wearable Paper-Based Sweat Sensor for Human Perspiration Monitoring. Adv Healthc Mater. 2019;8(16): e1900342. 